sues for children and co-morbidity and longevity factors for the elderly also need to be evaluated.

Merkatz believes that including these subgroups will speed the time that a drug takes to reach the market. If so, these costs pale into insignificance compared with the huge revenue of drug sales. "By not including women in Phase I and II trials, important pharmacokinetic information and dose ranging studies that are done in early studies will not be noticed until Phase III for women, thus slowing drug development," says Merkatz.

The September women's rule was driven largely by recommendations of the National AIDS Drug Development Task Force, convened two years ago and co-chaired by David Kessler (former FDA Commissioner) and Harold Varmus (director of the NIH), with representatives from the pharmaceutical industry, consumer groups and academia. This seems ironic, because the majority of today's most promising HIV compounds have already been tested in a significant number of women and children.

For many pharmaceutical companies, the importance of representing a population that is to be the recipient of a drug is not overlooked. But one important caveat exists: these trials have largely been Phase III studies, which raises an insidious problem of including women of childbearing age in earlier trials-teratogenicity. Although general toxicology tests are carried out before drugs enter human trials (to determine safety to major organ systems), quite often reproductive toxicology assessments have not been made at this stage. This is because many drugs drop out of development early on, before they are ever used in fertile women, making reproductive toxicology testing redundant. This is precisely why women have been excluded from Phase 1/II trials in the past, and is the main drawback to the women's rule.

To compensate for this, women will have to sign informed consent documents and refrain from becoming pregnant; but experience has shown that this never completely eliminates the risk. One solution would be an FDA rule to require that all animal toxicology tests are done before a drug enters human trials, but many acknowledge that introducing this step into drug development would definitely increase costs and slow down the process.

KAREN BIRMINGHAM

\title{
The UK endorses DIY genetic screening
}

The UK has become one of the first countries in the world to endorse mail-order genetic screening. But in doing so, the Department of Health has announced a stringent list of requirements that it says it will expect to be met by any company planning to market genetic screening tests directly to the public.

These requirements include the need to follow accepted laboratory practices, to offer pre-test and post-test counseling at no extra charge, and to provide a second copy of the results to anyone taking

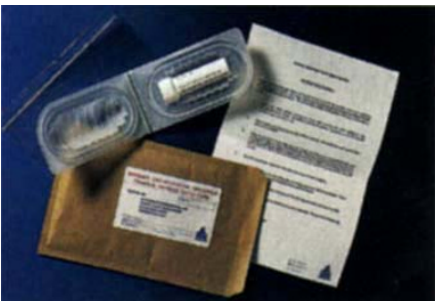

UDL's cystic fibrosis home test kit. those with genetic disorders, says that the voluntary guidelines "strike the right balance between encouragement and regulation." In particular, says Kent, by encouraging companies that obtain the ACGT's endorsement - and threatening to publish the names of those that do not the government "will discourage those who might be thinking of getting into the business to make a quick buck."

There has also been a cautious welcome from the companies whose activities will be cov-

the test for possible forwarding to their general practitioner - even if this has not been requested.

However, the government has stopped short of following the recommendation of a House of Commons Select Committee, made in a report published in July 1995, that it should set up an official regulatory body to control all companies offering screening. Defending this decision, public health minister Tessa Jowell said that she hoped companies offering such services would agree to abide by the voluntary guidelines, "thereby ensuring that such services are available without need for more formal controls."

Marcus Pembrey, Mothercare professor of pediatric genetics at the Institute of Child Health in London, and chairman of the Advisory Committee on Genetic Testing (ACGT), which drew up the guidelines, says that the decision not to propose mandatory regulations is an attempt to allow private services to develop in a responsible way. But he points to one recommendation accepted by the government, namely that the ACGT should publish annual lists not only of companies that have obtained the committee's endorsement of their screening services but also of those that have refrained from applying for such a sanction - an implicit "black list." If instances of abuse occur, some type of licensing scheme may have to be introduced, says Pembrey.

The government's approach has been generally welcomed. Alistair Kent, director of the Genetics Interest Group, an alliance of charities and support groups for ered. Paul Debenham, the chief executive of London-based University Diagnostics Limited (UDL), says that there are several points on which he takes issue with the government; for $\mathrm{ex}$ ample, he would like the guidelines to ried out by the National Health Service (NHS). UDL claims that its do-it-yourself mouthwash cystic fibrosis (CF) test, which analyzes 16 of the most common deletions seen in the UK population and accounts for 92 percent of all CF cases, is more comprehensive than that used in NHS laboratories.

But Debenham, whose company has two other mail-order DNA-based tests currently in the pipeline, applauds the decision to hold back from strictly defined regulation, or even legislation.

For the foreseeable future, the committee anticipates that only kits for common inherited recessive disorders, such as CF and hemochromatosis, that have no significant direct health implications for the carrier individual are likely to meet its criteria for approval, such as the provision of adequate pre-test and post-test counseling. Meeting these conditions is likely to be more difficult for complex diseases such as breast cancer, where the discovery of a mutation has important implications for the individual and close relatives. "We would be very surprised if any commercial company had the national infrastructure needed to offer the minimal acceptable level of support," says Pembrey.

DAVID DiCKSON London apply equally to genetic screening car- 